\title{
Inhalation of low-dose desflurane prevents the hemodynamic instability caused by target-controlled infusion of remifentanil and propofol during laparoscopic gynecological surgery: A randomized controlled trial
}

\author{
PENG ZHAO, YUNFENG CUI, LIHUA SUN and XUFANG SUN \\ Department of Anesthesiology, The Second Hospital of Jilin University, Changchun, Jilin 130041, P.R. China
}

Received March 18, 2019; Accepted September 10, 2020

DOI: $10.3892 /$ etm.2020.9486

\begin{abstract}
The objective of the present study was to determine whether the addition of inhaled desflurane is superior to remifentanil-propofol total intravenous anesthesia (TIVA) alone in patients undergoing laparoscopic gynecological surgery. A total of 60 patients who were scheduled to undergo laparoscopic gynecological surgery were prospectively enrolled and randomly allocated to receive either propofol-remifentanil (PR group; $n=30$ ) or combined propofol-remifentanil and low-dose desflurane (PRD group; $n=30$ ) for the maintenance of anesthesia. Hemodynamics [mean arterial pressure (MAP); heart rate (HR)], recovery parameters and complications were recorded. The results of the present study indicated that the addition of desflurane significantly reduced the amount of propofol and remifentanil that was administered in the PRD group, compared with that in the PR group. MAP and HR were significantly higher at T3 (5 min post-pneumoperitoneum), but significantly lower at T4 (removal of pneumoperitoneum needle) and T5 (post-operation immediately) in the PR group, compared with the PRD group. Moreover, MAP and HR were significantly altered at multiple time points within the PR group; however, they were relatively stable in the PRD group. There were no significant differences in the recovery parameters and complications between the two groups. In conclusion, combining low-dose desflurane with PR may represent an efficient anesthesia regimen to prevent the hemodynamic instability of TIVA in patients undergoing laparoscopic gynecological surgery.
\end{abstract}

Correspondence to: Dr Xufang Sun, Department of Anesthesiology, The Second Hospital of Jilin University, 218 Ziqiang Street, Nanguan, Changchun, Jilin 130041, P.R. China

E-mail: sunxufang8933@163.com

Key words: laparoscopic gynecological surgery, total intravenous anesthesia, inhaled anesthetics, propofol-remifentanil, desflurane, hemodynamic stability

\section{Introduction}

Laparoscopic surgery is a widely recommended procedure for excision of gynecological lesions, such as a cyst or cancer of the ovary or the uterine, owing to lower postoperative pain, a better aesthetic result and earlier discharge and recovery compared with laparotomy (1). Laparoscopic surgery is usually performed under general anesthesia, and a targetcontrolled intravenous infusion of propofol-remifentanil (PR) is the most common anesthetic regimen administered during laparoscopic gynecological surgery $(2,3)$. Previous studies have suggested that this combination allows rapid onset and recovery from anesthesia, and reduces the incidence of complications, such as postoperative nausea and vomiting (PONV), pain, agitation or other various adverse sequelae, thereby improving the quality of recovery (4-6). However, cardiovascular depression and hemodynamic instability, which are potentially fatal, have been reported to develop during the induction of anesthesia $(7,8)$. Therefore, additional anesthetic agents that do not result in cardiovascular depression and hemodynamic instability may be required to be combined with $\mathrm{PR}$.

In addition to intravenous anesthesia, inhaled anesthetics are also another commonly used approach in clinical practice (9). It has been reported that inhaled anesthetics regulate the hemodynamic response of the patients and resulted in muscle relaxation (10). However, inhaled anesthetics have also been indicated to exhibit certain disadvantages, such as prolonged recovery time after surgery and a higher incidence of postoperative agitation, which lessen patient satisfaction (11). Therefore, researchers have been making efforts to identify novel inhaled anesthetics. Desflurane is a novel fluorine halogenated methyl ether and is categorized as an inhaled anesthetic. The blood gas solubility of desflurane is only 0.49 , which is lower compared with that of other inhaled anesthetics (such as isoflurane, 1.27; sevoflurane, 0.62; halothane, 2.46) (12), and therefore, allows for a fast alveolar equilibration of desflurane and exhibits rapid onset/recovery characteristics (13-15). Accordingly, we hypothesized that supplementary inhalation of desflurane may not only prevent the adverse effects of cardiovascular depression and hemodynamic instability, but also may not influence the anesthetizing effects of the PR regimen, which has not yet 
been investigated in laparoscopic gynecological surgery, to the best of our knowledge (16).

The purpose of the present study was to determine whether the combination of inhaled desflurane is superior to PR total intravenous anesthesia alone in patients undergoing laparoscopic gynecological surgery, especially with regard to the effects on the hemodynamic stability.

\section{Materials and methods}

Patients. The present study was approved by the Ethics Committee of the Second Hospital of Jilin University (Changchun, China; approval no. 2018-010) and registered in the Chinese Clinical Trial Register (trial registration no. ChiCTR1800015017; http://www.chictr.org.cn/index.aspx). The objective and methods of the present study were explained to all patients, and written informed consent was obtained. All protocols were performed in accordance with the principles of the Declaration of Helsinki.

A total of 60 adult female patients (median age, 41 years) who were scheduled to undergo laparoscopic gynecological surgery at the Second Hospital of Jilin University (Changchun, China) were enrolled between January 2018 and June 2018. All patients had to meet the following inclusion criteria: i) aged between 18 and 60 years; ii) classified as American Society of Anesthesiologists (ASA) physical status I and II (17); iii) exhibit no heart, lung or brain diseases; iv) exhibit no history of diabetes and hypertension; v) present normal liver and kidney function, electrolytes, blood routine and coagulation test results preoperatively; and vi) present no abnormality in the electrocardiogram and chest X-ray. Patients who exhibited a history of: i) alcohol and/or drug abuse; ii) cardiovascular diseases with cardiovascular agents used and New York Heart Association classification as III or IV (18); iii) bradyarrhythmia (sinus bradycardia, left bundle branch block or third-degree atrioventricular block); iv) abnormal liver and kidney function; and v) allergy to any of the study drugs, were excluded from the present study.

Patients were randomly allocated via a computer-based random distribution to receive either $\mathrm{PR}$ or combined $\mathrm{PR}$ and desflurane (PRD) for the maintenance of anesthesia.

Anesthetic protocol. Upon arrival to the surgical room, all patients routinely received two-lead electrocardiography, peripheral oximetry, capnography, non-invasive blood pressure and bispectral index (BIS) monitoring. Following pre-oxygenation for $3 \mathrm{~min}$, midazolam at $0.05 \mathrm{mg} / \mathrm{kg}$, fentanyl at $4 \mu \mathrm{g} / \mathrm{kg}$, etomidate at $0.3 \mathrm{mg} / \mathrm{kg}$ and cisatracurium at $0.15 \mathrm{mg} / \mathrm{kg}$ were administered to the patients for the induction of anesthesia. Anesthesia was maintained by an intravenous infusion of propofol and remifentanil, which were designed to achieve a target effect-site concentration of $2 \mathrm{mg} / \mathrm{ml}$ and $4 \mathrm{ng} / \mathrm{ml}$, respectively, via a target-controlled infusion system (Orchestra ${ }^{\circledR}$ Base Primea; Fresenius Vial S.A.S.). Following endotracheal intubation, the patients in the PRD group received inhalation of desflurane at an oxygen flow rate of 2 $1 \mathrm{~min}$ and an expired end-tidal concentration of $3 \%$.

During the surgery, the concentrations of propofol and remifentanil were titrated to maintain the mean arterial blood pressure (MAP) within $20 \%$ of the baseline values. When
MAP was continuously $>10 \%$ of the baseline values for $1 \mathrm{~min}$ and BIS was $>60$, the concentration of propofol and remifentanil was increased by $0.5 \mu \mathrm{g} / \mathrm{kg}$ and $0.5 \mathrm{ng} / \mathrm{ml}$, respectively; if BIS was 40-60, only the concentration of remifentanil was increased by $0.5 \mathrm{ng} / \mathrm{ml}$. When MAP was continuously $<10 \%$ of the baseline values for $1 \mathrm{~min}$ and BIS was $<40$, the concentration of propofol and remifentanil was decreased by $0.5 \mu \mathrm{g} / \mathrm{kg}$ and $0.5 \mathrm{ng} / \mathrm{ml}$, respectively; if BIS was 40-60, only the concentration of remifentanil was decreased by $0.5 \mathrm{ng} / \mathrm{ml}$. When MAP was $<20 \%$ of the baseline values, ephedrine at $10 \mathrm{mg}$ was administered. If the patient's heart rate (HR) was decreased to $<45$ beats per minute (BPM), atropine $(0.5 \mathrm{mg})$ was administered.

Postoperatively, the oxygen flow rate of desflurane was adjusted to $6 \mathrm{l} / \mathrm{min}$ to promote the removal of desflurane, followed by the removal of the laparoscopic instruments, the suture and the termination of propofol infusion. Atropine $(0.01 \mathrm{mg} / \mathrm{kg})$ and neostigmine $(0.02 \mathrm{mg} / \mathrm{kg})$ were administered to counteract the cisatracurium-induced neuromuscular block, while flumazenil $(0.5 \mathrm{mg})$ was administered for antagonism of the residual sedative effects of midazolam. No patients received naloxone for awakening. Patients were extubated when the following conditions were met: i) stable autonomic respiratory rhythm; ii) tidal volume $>6 \mathrm{ml} / \mathrm{kg}$; iii) peripheral capillary oxygen saturation $>95 \%$ for $5 \mathrm{~min}$; iv) patient endtidal carbon dioxide $<45 \mathrm{mmHg}$; and v) recovery of protective reflex and ability to open their eyes on verbal commands, followed by transfer from the operating room to the staffed post-anesthesia care unit. When modified Aldrete Recovery Score was $\geq 9$ (19), the patients were discharged to the ward.

Measurement. Hemodynamics, including MAP and HR, were measured upon arrival to the surgical room (T0), immediately at intubation (T1), immediately at operation initiation (T2), 5 min post-pneumoperitoneum (T3), at removal of pneumoperitoneum needle (T4), immediately at post-operation (T5), immediately at extubation (T6), following extubation for $5 \mathrm{~min}$ (T7) and $10 \mathrm{~min}$ (T8).

Records were made on intraoperative intake, estimated blood loss, intraoperative urine output, consumption of remifentanil and propofol and the time of operation, anesthesia, eye-opening on verbal commands, extubation, orientation recovery and achievement of a modified Aldrete recovery score $(19) \geq 9$.

Observer's Assessment of Alertness and Sedation (OAA/S) score was assessed preoperatively and postoperatively to predict the sedation status, which was rated on a 5-point scale as follows: 5, alert; 4, lethargic; 3 , awakened by voice; 2 , awakened by shaking; and 1, deep sleep (20). The Sedationagitation scale (SAS) was evaluated at T6 and T8 to predict the agitation status, which was rated on a 7-point scale, with a $\geq 5$ score diagnosed as emergence agitation (21). Postoperative pain was assessed using the visual analogue scale [VAS; range, $0-10$ (0 represents no pain and 10 represents the worst imaginable pain)] (22) at T8 and $1 \mathrm{~h}$ after the operation. VAS $>4$ indicated the occurrence of postoperative pain. Intravenous fentanyl $(0.1 \mathrm{mg})$ was the first-line rescue analgesic, and pethidine $(50 \mathrm{mg}$ ) was used as the second-line rescue analgesic on demand. All scores were assessed by the same anesthesiologists in a blinded fashion to the grouping of the trial. 


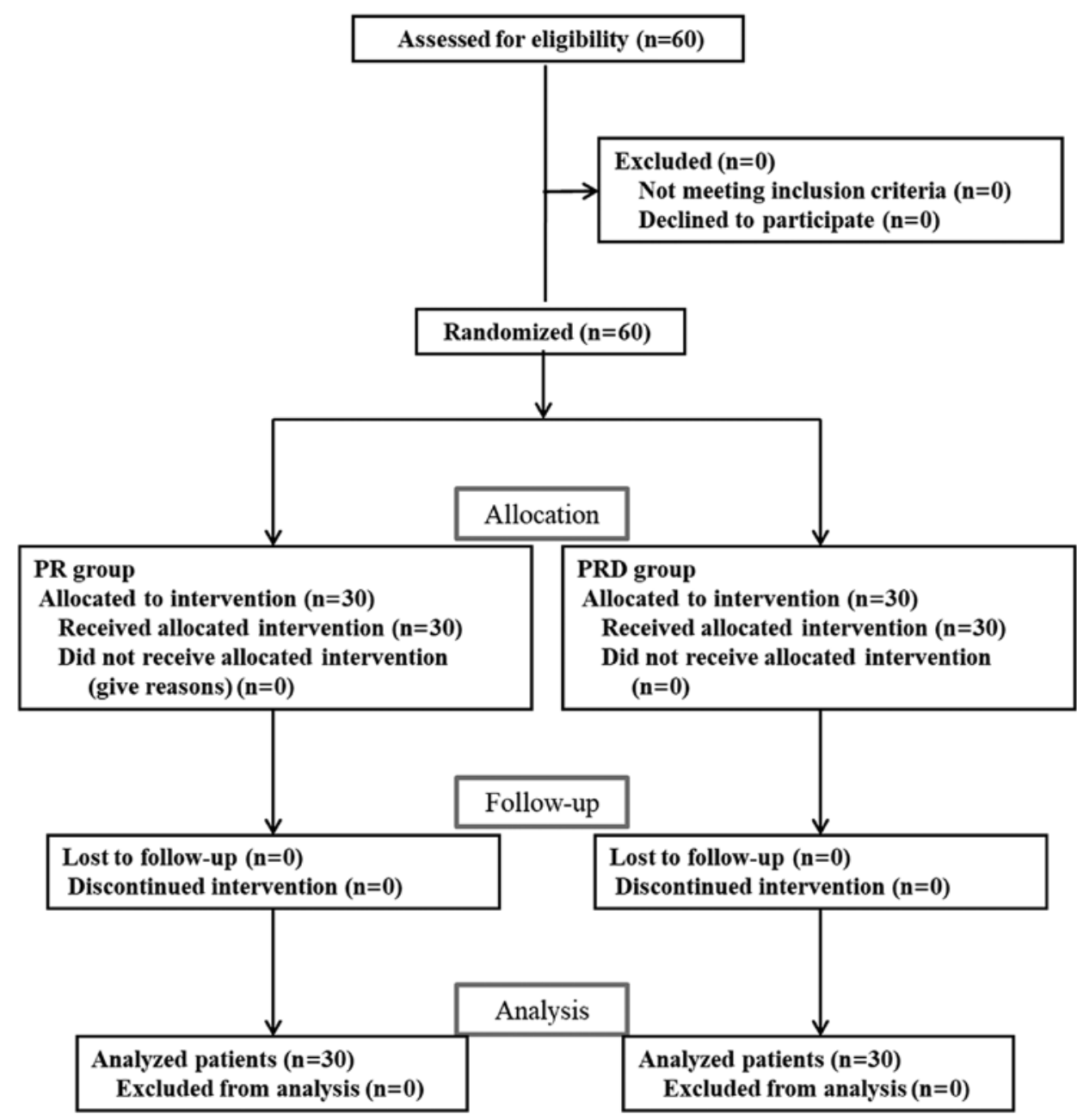

Figure 1. Flow diagram of the present study.

Postoperative nausea was defined as a subjectively unpleasant sensation associated with an awareness of the urge to vomit, whereas an episode of vomiting was defined as vomiting (forceful expulsion of gastric contents from the mouth) and retching (spasmodic, labored and rhythmic contractions of the respiratory muscles without expulsion of gastric contents). When the patients either vomited or retched, $0.3 \mathrm{mg}$ ramosetron was injected intravenously as a rescue treatment, if treatment was requested. In addition, other postoperative complications, including respiratory depression, shivering and bradycardia, were also recorded.

Statistical analysis. The sample size was calculated using GraphPad InStat version 3.0 software (GraphPad Software, Inc.). The calculation revealed that 27 subjects per group were required to achieve a power of $90 \%$ with a type I error of 0.05 . To allow for a dropout rate of up to $10 \%, 30$ subjects were designed to be enrolled in each group. Categorical data are presented as number (\%) and are compared between groups using $\chi^{2}$ test or Fisher's exact test. Non-Gaussian continuous data are presented as the median (minimum-maximum) and are compared between groups using the Mann-Whitney U test. Normally distributed continuous data are presented as the mean \pm SD and are compared between groups using twosample independent Student's t-test. A mixed-design repeated measures ANOVA followed by Bonferroni's multiple comparisons test was used to compare MAP and HR within (different time points) and between PR and PRD groups. $\mathrm{P}<0.05$ was considered to indicate a statistically significant difference. Statistical analysis was performed using SPSS v23.0 software (IBM Corp.).

\section{Results}

Study population. Between January 2018 and June2018, 60 patients were enrolled in the present study, and no dropout occurred. These 60 patients were subsequently randomly allocated to receive PR or combined PRD for the maintenance of anesthesia, with 30 patients in each group (Fig. 1). No significant differences were observed between the two groups with regard to the patients' demographics, including age, body weight, ASA classification and the cause of the laparoscopic gynecological surgery, indicating that both groups were comparable (Table I).

Impact on perioperative characteristics. Surgery and anesthesia were uneventful in all patients. The perioperative characteristics were also recorded and compared. The results indicated no significant differences were observed in the intraoperative intake, estimated blood loss, intra-operative urine 
Table I. Demographic data of the population of the present study.

\begin{tabular}{lcc}
\hline Variables & PR group (n=30) & PRD group (n=30) \\
\hline Mean age \pm SD, years & $41.46 \pm 10.97$ & $38.87 \pm 9.63$ \\
Mean weight \pm SD, kg & $62.23 \pm 7.34$ & $59.80 \pm 5.00$ \\
Median height (minimum-maximum), cm & $160(151-170)$ & $160(155-169)$ \\
ASA physical status, n (\%) & & 0.333 \\
I & $6(20.0)$ & $7(23.3)$ \\
II & $24(80.0)$ & $23(76.7)$ \\
Type of surgery, n (\%) & & $7(23.3)$ \\
Ovarian cystectomy & $6(20.0)$ & $10(33.3)$ \\
Hysterectomy & $9(30.0)$ & $13(43.3)$ \\
Myomectomy & $15(50.0)$ & 0.834 \\
\hline
\end{tabular}

PR, propofol-remifentanil; PRD, PR and low-dose desflurane; ASA, American Society of Anesthesiologists.

Table II. Patients' perioperative characteristics.

\begin{tabular}{lccr}
\hline Variables & PR group $(\mathrm{n}=30)$ & PRD group $(\mathrm{n}=30)$ & P-value \\
\hline Intra-operative intake, $\mathrm{ml}$ & $500(300-800)$ & $500(300-800)$ & 0.515 \\
Estimated blood loss, ml & $100(50-300)$ & $55(50-300)$ & 0.271 \\
Intra-operative urine output, ml & $100(50-280)$ & $90(50-350)$ & 0.847 \\
Operation time, min & $70(50-150)$ & $65(40-169)$ & 0.853 \\
Anesthesia time, min & $99(65-165)$ & $85(75-185)$ & 0.911 \\
Consumption of anesthetics & & & 0.242 \\
Cisatracurium, mg & $14(12-35)$ & $12.5(12-25)$ & $<0.001$ \\
Remifentanil, mg & $1.56(0.96-4.36)$ & $0.90(0.20-2.88)$ & $212.33 \pm 62.85$
\end{tabular}

Non-Gaussian continuous data are presented as the median (minimum-maximum); normally distributed continuous data are presented as the mean \pm SD. PR, propofol-remifentanil; PRD, PR and low-dose desflurane.
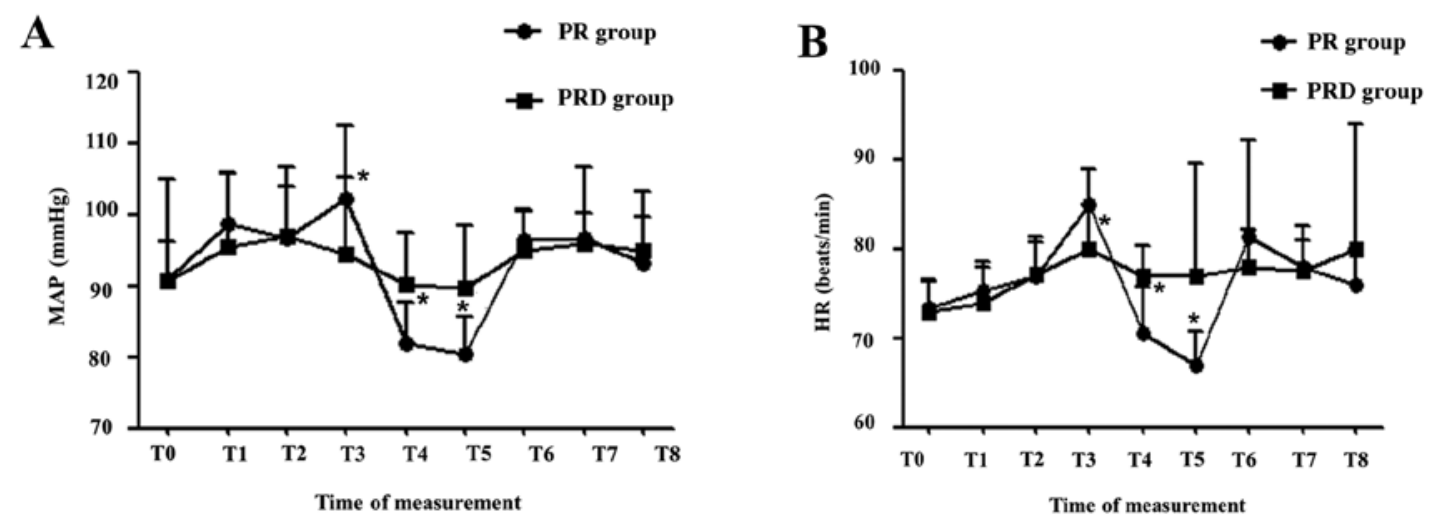

Figure 2. Hemodynamic responses to various stimuli during the perioperative period. (A) MAP. (B) HR. T0, upon arrival to the surgical room; T1, immediately at intubation; T2, immediately at operation initiation; T3, 5 min post-pneumoperitoneum; T4, removal of pneumoperitoneum needle; T5, immediately postoperation; T6, immediately at extubation; T7, 5 min following extubation; $\mathrm{T} 8,10 \mathrm{~min}$ following extubation. " $\mathrm{P}<0.05$ vs. PRD group. PR, propofol-remifentanil; PRD, PR and low-dose desflurane; MAP, mean arterial blood pressure, HR, heart rate.

output, operation time and anesthesia time between the two groups, but the addition of desflurane significantly decreased the consumption of propofol and remifentanil (Table II), indicating that the incidence of PR-induced complications, such 
Table III. Hemodynamic alterations at different points for each group.

\begin{tabular}{lccc}
\hline $\begin{array}{l}\text { Hemodynamic } \\
\text { parameter }\end{array}$ & $\begin{array}{c}\text { Time } \\
\text { point }\end{array}$ & $\begin{array}{c}\text { PR group } \\
(\mathrm{n}=30)\end{array}$ & $\begin{array}{c}\text { PRD group } \\
(\mathrm{n}=30)\end{array}$ \\
\hline MAP & T0 & $91.00 \pm 5.09$ & $90.73 \pm 14.32$ \\
& T1 & $98.63 \pm 6.99^{\mathrm{a}}$ & $95.47 \pm 10.49$ \\
& T2 & $96.60 \pm 7.34$ & $96.93 \pm 9.71$ \\
& T3 & $102.10 \pm 10.24^{\mathrm{a}, \mathrm{c}}$ & $94.33 \pm 10.92$ \\
& T4 & $82.03 \pm 5.58^{\mathrm{a}-\mathrm{d}}$ & $90.17 \pm 7.25^{\mathrm{c}}$ \\
& T5 & $80.50 \pm 5.05^{\mathrm{a}-\mathrm{d}}$ & $89.77 \pm 8.59^{\mathrm{c}}$ \\
& T6 & $96.50 \pm 3.98^{\mathrm{a}, \mathrm{e}, \mathrm{f}}$ & $95.00 \pm 5.63$ \\
HR & T7 & $96.60 \pm 10.05^{\mathrm{e}, \mathrm{f}}$ & $95.97 \pm 4.20^{\mathrm{e}, \mathrm{f}}$ \\
& T8 & $93.23 \pm 9.82^{\mathrm{d}-\mathrm{f}, \mathrm{g}}$ & $95.00 \pm 4.71$ \\
& T0 & $73.30 \pm 3.03$ & $73.00 \pm 3.55$ \\
& T1 & $75.30 \pm 3.17^{\mathrm{a}}$ & $74.00 \pm 3.91$ \\
& T2 & $77.00 \pm 4.39^{\mathrm{a}}$ & $77.23 \pm 3.46^{\mathrm{a}, \mathrm{b}}$ \\
& T3 & $85.03 \pm 3.96^{\mathrm{a}-\mathrm{c}}$ & $80.00 \pm 4.91^{\mathrm{a}, \mathrm{b}}$ \\
& T4 & $70.63 \pm 5.12^{\mathrm{b}-\mathrm{d}}$ & $77.00 \pm 3.35^{\mathrm{a}}$ \\
& T5 & $67.00 \pm 3.80^{\mathrm{a}-\mathrm{d}}$ & $76.87 \pm 12.67$ \\
& T6 & $81.33 \pm 10.75^{\mathrm{a}, \mathrm{e}, \mathrm{f}}$ & $78.00 \pm 4.18^{\mathrm{a}}$ \\
& T7 & $78.00 \pm 4.56^{\mathrm{a}, \mathrm{d}-\mathrm{f}}$ & $77.57 \pm 3.41^{\mathrm{a}}$ \\
& T8 & $76.00 \pm 3.85^{\mathrm{d}-\mathrm{f}}$ & $79.87 \pm 14.12$ \\
\hline
\end{tabular}

T0, upon arrival to the surgical room; T1, immediately at intubation; $\mathrm{T} 2$, immediately at operation initiation; T3, 5 min post-pneumoperitoneum; T4, removal of pneumoperitoneum needle; T5, immediately post-operation; T6, immediately at extubation; T7, 5 min following extubation; T8, $10 \mathrm{~min}$ following extubation. ${ }^{\mathrm{a}} \mathrm{P}<0.05 \mathrm{vs}$. $\mathrm{T} 0$; ${ }^{\mathrm{b}} \mathrm{P}<0.05$ vs. T1; ${ }^{\mathrm{P}}<0.05$ vs. $\mathrm{T} 2$; ${ }^{\mathrm{d}} \mathrm{P}<0.05$ vs. $\mathrm{T} 3$; ${ }^{\mathrm{e}} \mathrm{P}<0.05$ vs. $\mathrm{T} 4$; ${ }^{\mathrm{f}} \mathrm{P}<0.05$ vs. T5; ${ }^{\mathrm{P}}<0.05$ vs. T7. MAP, mean arterial blood pressure; HR, heart rate; PR, propofol-remifentanil; PRD, PR and low-dose desflurane.

as hemodynamic instability, may be reduced. This hypothesis was verified by the measurement of MAP and HR, which indicated that both MAP (Fig. 2A) and HR (Fig. 2B) were significantly higher at $\mathrm{T} 3$, but significantly lower at $\mathrm{T} 4$ and T5 in the PR group compared with the PRD group. In addition, within the PRD group, the MAP and HR were generally stable, with significant alterations only between a few time points (Table III). By contrast, significant differences in MAP and HR were observed at multiple time points within the PR group (Table III).

Impact on postoperative outcomes. Furthermore, postoperative recovery parameters and adverse events were also recorded and are presented in Tables IV and V. The results indicated that the two groups were comparable in eye-opening time, extubation time, orientation recovery time, time to achieve Aldrete score $\geq 9, \mathrm{OAA} / \mathrm{S}$ score and SAS score (Table IV). No significant difference was observed in the number of patients who experienced complications, including bradycardia, hypotension, agitation, PONV, nausea, vomiting and pain, between the two groups. The number of patients requiring rescue anti- emetic and postsurgical analgesia also did not differ between the two groups (Table V).

\section{Discussion}

Intravenously infused propofol and inhaled desflurane are two commonly used anesthetics that can be combined with the ultra-short-acting $\mu$-opioid receptor agonist remifentanil for the induction and maintenance of anesthesia during surgery. However, which combination is optimal remains unclear, and may be attributed to certain disadvantages of each anesthetic (23-27). For example, Cho et al (23) reported that tissue oxygen saturation was higher in the desflurane group compared with that in the propofol group at 30 and $60 \mathrm{~min}$ of ventilation. The recovery slope during the vascular occlusion test, reflecting microvascular reperfusion adequacy, was also higher in the desflurane compared with that in the propofol group during surgery (23). Mahli et al (24) reported that the general mean values of MAP and HR for the PR group were higher compared with that of the desfluraneremifentanil group $(89.3 \mathrm{mmHg}$ and $72.4 \mathrm{BPM}$ vs. $77.1 \mathrm{mmHg}$ and 69.5 BPM, respectively). These findings indicated that desflurane-remifentanil anesthesia may be associated with an improved microcirculation and hemodynamic stability compared with PR anesthesia (24). Yoo et al (6) demonstrated that the incidence of nausea in the post-anesthetic care unit (22.6 vs. $6.5 \% ; \mathrm{P}=0.001)$ and at $1-6 \mathrm{~h}$ postoperatively (54.8 vs. $16.1 \%$; $\mathrm{P}=0.001$ ) was significantly higher in the desflurane-remifentanil compared with that in the PR group. Zaballos et al (25) reported that the desflurane-remifentanil group received an increased amount of fentanyl as rescue analgesia compared with the PR group ( $200 \pm 65$ vs. $113 \pm 38 \mu \mathrm{g})$. Gritti et al (26) and Gozdemir et al (27) demonstrated that the recovery times for spontaneous ventilation, extubation, time to awakening, eye opening and ability to provide name and date of birth were shorter in the PR group compared with those in the desflurane group. These results suggested that PR may be more effective for recovery and associated with a decreased number of complications. Moreover, the concentration of each anesthetic was higher when only propofol or desflurane was used, resulting in non-negligible adverse outcomes (such as unstable hemodynamic responses and PONV) in the clinic (28). Therefore, we hypothesized that a combination of three drugs (desflurane, propofol and remifentanil) in lower doses may prevent their respective shortcomings and achieve improved anesthetizing effects. Although a previous study has recommended the supplementation of intravenous anesthesia with desflurane, it has not compared the effects of PR and PRD, but only compared the PRD with the desflurane group (16). Therefore, this is the first time, to the best of our knowledge, that a study compared the anesthetizing effects of a combination of lower-dose desflurane with PR. The results of the present study indicated that the PRD group not only exhibited a similar recovery potential and complications (such as low PONV) to the PR group, but also maintained stable hemodynamics. Although three drugs were used, the combined cost may be similar for the patients, as the dose of PR was significantly decreased in the PRD compared with the PR group, and the price of propofol and desflurane has been reported to be similar $(29,30)$. 
Table IV. Post-anesthesia recovery parameters.

\begin{tabular}{lccc}
\hline Variables & PR group $(\mathrm{n}=30)$ & PRD group (n=30) & P-value \\
\hline Eye-opening time, min & $7.00 \pm 1.97$ & $7.40 \pm 1.61$ & 0.392 \\
Extubation time, min & $10.00 \pm 2.44$ & $10.70 \pm 2.32$ & 0.259 \\
Orientation recovery time, min & $12.43 \pm 2.18$ & $13.47 \pm 2.32$ & 0.080 \\
Time to achieve Aldrete score $\geq 9$, min & $15.97 \pm 2.55$ & $16.53 \pm 2.54$ & 0.393 \\
OAA/S, $\mathrm{n}(5 / 4)$ & & & 0.401 \\
Preoperatively & $30 / 0$ & $30 / 0$ & 0.492 \\
1 h post-operation & $30 / 0$ & $29 / 1$ & \\
SAS, $\mathrm{n}(0-4 / 5-7)$ & & & $28 / 2$ \\
Extubation & $30 / 0$ & $30 / 0$ & \\
10 min after extubation & $30 / 0$ & & \\
\hline
\end{tabular}

PR, propofol-remifentanil; PRD, PR and low-dose desflurane; OAA/S, Observer's Assessment of Alertness and Sedation; SAS, sedationagitation scale.

Table V. Incidence of postoperative adverse reactions.

\begin{tabular}{|c|c|c|c|}
\hline Variables & PR group $(n=30)$ & PRD group $(n=30)$ & P-value \\
\hline Hypotension, n (\%) & $2(6.7)$ & $0(0)$ & 0.492 \\
\hline Bradycardia, n (\%) & $5(16.7)$ & $2(6.7)$ & 0.424 \\
\hline Agitation, n (\%) & $0(0.0)$ & $2(6.7)$ & 0.492 \\
\hline PONV, n (\%) & $1(3.3)$ & $1(3.3)$ & 1.000 \\
\hline Nausea, n (none/mild/moderate/severe) & $29 / 1 / 0 / 0$ & $29 / 1 / 0 / 0$ & 1.000 \\
\hline Vomiting, n (\%) & $0(0.0)$ & $0(0.0)$ & 1.000 \\
\hline Rescue antiemetic, n (\%) & $0(0.0)$ & $0(0.0)$ & \\
\hline \multicolumn{4}{|l|}{ VAS, n (0-3/4-6/7-10) } \\
\hline 10 min after extubation & $30 / 0 / 0$ & $30 / 0 / 0$ & 1.000 \\
\hline $1 \mathrm{~h}$ post-operation & $27 / 3 / 0$ & $22 / 8 / 0$ & 0.098 \\
\hline Pain, n (\%) & $3(10.0)$ & $8(26.7)$ & 0.095 \\
\hline \multicolumn{4}{|l|}{ Postsurgical analgesia, n (\%) } \\
\hline None & $27(90.0)$ & $22(73.3)$ & 0.098 \\
\hline Fentanyl & $3(10.0)$ & $8(26.7)$ & \\
\hline Fentanyl + pethidine & $0(0.0)$ & $0(0.0)$ & \\
\hline
\end{tabular}

PR, propofol-remifentanil; PRD, PR and low-dose desflurane; PONV, postoperative nausea and vomiting; VAS, visual analogue scale.

Several limitations to the present study exist. Firstly, although the power analysis indicated that the number of patients who were required in the present study was sufficient, the population size was relatively small and this was a singlecenter study. This may be an underlying reason explaining statistically non-significant differences in postoperative adverse reactions between the PRD and PR groups and the lower PONV observed (1/30 patients, 3.3\%) compared with previous reports $(20-50 \%)(4,31,32)$. Secondly, the enrolled patients were relatively young and whether the conclusion is similar in an older population requires further validation. Thirdly, a desflurane-remifentanil control group should have been included. Fourthly, only one kind of surgery, such as ovarian cystectomy, should be included in future trials, in order to more easily control the operation and anesthesia time and reduce its influence on the postoperative pain. For example, the fact that the incidence of pain was relatively higher in the PRD compared with that in the PR group may be attributed to the increased number of patients $(3 / 8)$ who underwent myomectomy among the patients with pain. Fifthly, a cost analysis with the use of the three agents was not a part of the present study. Finally, more outcomes, including the incidence of intraoperative awareness and body movement, and mechanism parameters, such as alterations in the stress response (catecholamines, noradrenaline, adrenaline, adrenocorticotropic hormone and cortisol) or inflammation factors (interleukin-6, tumor necrosis factor- $\alpha$, C-reactive protein and nitric oxide) $(33,34)$ should be recorded to comprehensively 
assess the anesthetizing effects of lower-dose desflurane combined with PR.

The present study suggested that combining low-dose desflurane with PR may represent an efficient anesthesia regimen to prevent the hemodynamic instability of total intravenous anesthesia for patients undergoing laparoscopic gynecological surgery.

\section{Acknowledgements}

Not applicable.

\section{Funding}

No funding was received.

\section{Availability of data and materials}

All data generated or analyzed during the present study are included in this published article.

\section{Authors' contributions}

PZ and XS participated in the conception and design of the study. PZ and YC collected the data and performed the statistical analysis. LS was involved in the interpretation of the data. PZ drafted the manuscript. XS revised the manuscript for important intellectual content. All authors read and approved the final manuscript.

\section{Ethics approval and consent to participate}

The present study was approved by the Ethics Committee of the Second Hospital of Jilin University (Changchun, China; approval no. 2018-010) and written informed consent was obtained from all patients.

\section{Patient consent for publication}

Not applicable.

\section{Competing interests}

The authors declare that they have no competing interests.

\section{References}

1. Koo YJ, Kim JE, Kim YH, Hahn HS, Lee IH, Kim TJ, Lee KH, Shim JU and Lim KT: Comparison of laparoscopy and laparotomy for the management of early-stage ovarian cancer: Surgical and oncological outcomes. J Gynecol Oncol 25: 111-117, 2014.

2. Zhang D and Nie A: Assessment of different anesthesia depth under total intravenous anesthesia on postoperative cognitive function in laparoscopic patients. J Res Med Sci 21: 73, 2016.

3. Carli D, Meletti JFA, Neto NEU, Martinez G, Kim ALC and de Camargo RPS: General anesthesia technique and perception of quality of postoperative recovery in women undergoing cholecystectomy: A randomized, double-blinded clinical trial. PLoS One 15: e0228805, 2020.

4. Lee WK, Kim MS, Kang SW, Kim S and Lee JR: Type of anaesthesia and patient quality of recovery: A randomized trial comparing propofol-remifentanil total i.v. anaesthesia with desflurane anaesthesia. Br J Anaesth 114: 663-668, 2015.
5. Ryu JH, Kim JH, Park KS and Do SH: Remifentanil-propofol versus fentanyl-propofol for monitored anesthesia care during hysteroscopy. J Clin Anesth 20: 328-332, 2008.

6. Yoo YC, Bai SJ, Lee KY, Shin S, Choi EK and Lee JW: Total intravenous anesthesia with propofol reduces postoperative nausea and vomiting in patients undergoing robot-assisted laparoscopic radical prostatectomy: A prospective randomized trial. Yonsei Med J 53: 1197-1202, 2012.

7. Son I, Oh CS, Choi JW and Kim SH: The effect of sufentanil administration on remifentanil-based anaesthesia during laparoscopic gynaecological surgery: A double-blind randomized controlled trial. ScientificWorldJournal 2014: 701329, 2014.

8. Beier SL, Mattoso CR, Aguiar AJ, Vianna PT and Massone F: Hemodynamic effects of target-controlled infusion of propofol alone or in combination with a constant-rate infusion of remifentanil in dogs. Can J Vet Res 79: 309-315, 2015.

9. Herling SF, Dreijer B, Wrist Lam G, Thomsen T and Møller AM: Total intravenous anaesthesia versus inhalational anaesthesia for adults undergoing transabdominal robotic assisted laparoscopic surgery. Cochrane Database Syst Rev 4: CD011387, 2017.

10. Bharti N, Chari P and Kumar P: Effect of sevoflurane versus propofol-based anesthesia on the hemodynamic response and recovery characteristics in patients undergoing microlaryngeal surgery. Saudi J Anaesth 6: 380-384, 2012.

11. Ionescu D, Mărgărit S, Vlad L, Iancu C, Alexe A, Deac D, Răduţ A, Tudorică G, Necula A and Pop T: TIVA-TCI (Total IntraVenous Anesthesia-Target Controlled Infusion) versus isoflurane anesthesia for laparoscopic cholecystectomy. Postoperative nausea and vomiting, and patient satisfaction. Chirurgia (Bucur) 104: 167-172, 2009 (In Romanian).

12. Yasuda N, Eger EI II, Weiskopf RB, Tanifuji Y and Kobayashi K: Solubility of desflurane (I-653), sevoflurane, isoflurane, and halothane in human blood. Masui 40: 1059-1062, 1991 (In Japanese).

13. Eger EI II: New inhaled anesthetics. Anesthesiology 80: 906-922, 1994.

14. Jindal R, Kumra VP, Narani KK and Sood J: Comparison of maintenance and emergence characteristics after desflurane or sevoflurane in outpatient anaesthesia. Indian $\mathbf{J}$ Anaesth 55: 36-42, 2011.

15. Kotwani MB and Malde AD: Comparison of maintenance, emergence and recovery characteristics of sevoflurane and desflurane in pediatric ambulatory surgery. J Anaesthesiol Clin Pharmacol 33: 503-508, 2017.

16. Boat A, Mahmoud M, Michelfelder EC, Lin E, Ngamprasertwong P, Schnell B, Kurth CD, Crombleholme TM and Sadhasivam S: Supplementing desflurane with intravenous anesthesia reduces fetal cardiac dysfunction during open fetal surgery. Paediatr Anaesth 20: 748-756, 2010.

17. Daabiss M: American Society of Anaesthesiologists physical status classification. Indian J Anaesth 55: 111-115, 2011.

18. Bredy C, Ministeri M, Kempny A, Alonso-Gonzalez R, Swan L, Uebing A, Diller GP, Gatzoulis MA and Dimopoulos K: New York Heart Association (NYHA) classification in adults with congenital heart disease: Relation to objective measures of exercise and outcome. Eur Heart J Qual Care Clin Outcomes 4: 51-58, 2018

19. Ead H: From Aldrete to PADSS: Reviewing discharge criteria after ambulatory surgery. J Perianesth Nurs 21: 259-267, 2006.

20. Chernik DA, Gillings D, Laine H, Hendler J, Silver JM, Davidson AB, Schwam EM and Siegel JL: Validity and reliability of the Observer's Assessment of Alertness/Sedation Scale: Study with intravenous midazolam. J Clin Psychopharmacol 10: 244-251, 1990.

21. Namigar T, Serap K, Esra AT, Özgül O, Can ÖA, Aysel A and Achmet A: The correlation among the Ramsey sedation scale, Richmond agitation sedation scale and Riker sedation agitation scale during midazolam-remifantanil sedation. Braz $\mathbf{J}$ Anesthesiol 67: 347-354, 2016.

22. Langley GB and Sheppeard H: The visual analogue scale: Its use in pain measurement. Rheumatol Int 5: 145-148, 1985.

23. Cho YJ, Bae J, Kim TK, Hong DM, Seo JH, Bahk JH and Jeon Y: Microcirculation measured by vascular occlusion test during desflurane-remifentanil anesthesia is superior to that in propofolremifentanil anesthesia in patients undergoing thoracic surgery: Subgroup analysis of a prospective randomized study. J Clin Monit Comput 31: 989-997, 2017. 
24. Mahli A, Coskun D, Karaca GI, Akcali DT, Karabiyik L and Karadenizli Y: Target-controlled infusion of remifentanil with propofol or desflurane under bispectral index guidance: Quality of anesthesia and recovery profile. J Res Med Sci 16: 611-620, 2011.

25. Zaballos M, Reyes A, Etulain J, Monteserín C, Rodríguez M and Velasco E: Desflurane versus propofol in post-operative quality of recovery of patients undergoing day laparoscopic cholecystectomy. Prospective, comparative, non-inferiority study. Rev Esp Anestesiol Reanim 65: 96-102, 2018 (In Spanish).

26. Gritti P, Carrara B, Khotcholava M, Bortolotti G, Giardini D, Lanterna LA, Benigni A and Sonzogni V: The use of desflurane or propofol in combination with remifentanil in myasthenic patients undergoing a video-assisted thoracoscopic-extended thymectomy. Acta Anaesthesiol Scand 53: 380-389, 2009.

27. Gozdemir M, Sert H, Yilmaz N, Kanbak O, Usta B and Demircioglu RI: Remifentanil-propofol in vertebral disk operations: Hemodynamics and recovery versus desflurane-n(2) o inhalation anesthesia. Adv Ther 24: 622-631, 2007.

28. Chen PN, Lu IC, Chen HM, Cheng KI, Tseng KY and Lee KT: Desflurane reinforces the efficacy of propofol target-controlled infusion in patients undergoing laparoscopic cholecystectomy. Kaohsiung J Med Sci 32: 32-37, 2016.

29. Lin CY, Wong CS and Wu CT: Cost analysis of three anesthetic regimens under auditory evoked potential monitoring in gynecologic laparoscopic surgery. Acta Anaesthesiol Taiwan 46: 53, author reply 53-54, 2008.
30. Demeere JL, Merckx Ch and Demeere N: Cost minimisation and cost effectiveness in anaesthesia for total hip replacement surgery, in Belgium? A study comparing three general anaesthesia techniques. Acta Anaesthesiol Belg 57: 145-151, 2006.

31. Seki H, Furumoto K, Sato M, Kagoya A, Hashimoto H, Sekiguchi Y and Nakatsuka I: Effects of epidural anesthesia on postoperative nausea and vomiting in laparoscopic gynecological surgery: A randomized controlled trial. J Anesth 32: 608-615, 2018.

32. Uchinami Y, Takikawa S, Takashima F, Maeda Y, Nasu S, Ito A and Saito T: Incidence of postoperative nausea and vomiting is not increased by combination of low concentration sevoflurane and propofol compared with propofol alone in patients undergoing laparoscopic gynecological surgery. JA Clin Rep 5: 70, 2019. DOI: $10.1186 /$ s40981-019-0292-4.

33. Marana E, Russo A, Colicci S, Polidori L, Bevilacqua F, Viviani D and Di Stasio E: Desflurane versus sevoflurane: a comparison on stress response. Minerva anestesiologica 79: 7-14, 2013.

34. Roh GU, Song Y, Park J, Ki YM and Han DW: Effects of propofol on the inflammatory response during robot-assisted laparoscopic radical prostatectomy: A prospective randomized controlled study. Sci Rep 9: 5242, 2019.

(i) $\Theta$ This work is licensed under a Creative Commons Attribution-NonCommercial-NoDerivatives 4.0 International (CC BY-NC-ND 4.0) License. 